\title{
Student Teachers, Professional Development and Effectiveness: The Role of Resilience in Enhancing the Culture of Learning and Teaching
}

\author{
Vuyisile Msila \\ Thabo Mbeki African School of Public and International Affairs, University of South Africa, Pretoria, 0003, Gauteng, South Africa
}

Received July 15, 2021; Revised September 17, 2021; Accepted September 29, 2021

\section{Cite This Paper in the following Citation Styles}

(a): [1] Vuyisile Msila, "Student Teachers, Professional Development and Effectiveness: The Role of Resilience in Enhancing the Culture of Learning and Teaching," Universal Journal of Educational Research, Vol. 9, No. 10, pp. 1794 1804, 2021. DOI: 10.13189/ujer.2021.091008.

(b): Vuyisile Msila (2021). Student Teachers, Professional Development and Effectiveness: The Role of Resilience in Enhancing the Culture of Learning and Teaching. Universal Journal of Educational Research, 9(10), 1794 - 1804. DOI: 10.13189/ujer.2021.091008.

Copyright $\odot 2021$ by authors, all rights reserved. Authors agree that this article remains permanently open access under the terms of the Creative Commons Attribution License 4.0 International License

\begin{abstract}
Student teachers in their initial teacher training get time to visit schools and observe and put various theories into practice. Practice teaching is the beginning of the journey towards professionalism. Yet many student teachers who visit schools in South Africa witness grim realities in different schools. Several South African education experts have written about two kinds of school systems; one is schools serving the affluent families whilst the other, numerous schools serve the indigent families and children who are faced with adversity in society. This case study examines the role of teachers in engendering hope and emotional strength among learners who face hardships. Exposed to challenging conditions in their practice teaching schools, the 10 student teachers tried to develop themselves as well as the learners through the fostering of resilience. The conclusions found that facilitating resilience among learners who face adversity is one powerful remedy in creating affable school climate and invitational classrooms. Teachers who instill this in their classrooms may have a long fulfilling career as teachers who are both life-long learners and professionally matured whilst their learners overcome their personal challenges as they face classrooms with emotional stability.
\end{abstract}

Keywords Practice Teaching, Professional Maturity, Resilience, School Effectiveness

\section{Introduction}

Student teachers in initial teacher training programs are supposed to have the most exciting times in schools as they do their practice teaching. When out there teaching they get to try out various teaching strategies they have learnt in their higher education institutions. Practice teaching of student teachers is the beginning of a journey for life-long professional development. It enables them to try out the theories learnt in their university classes in the actual classrooms. It is a process of practice teaching but, in reality, the student teachers also practise learning [1]. This means that student teachers will also learn several aspects of teaching when they are in schools that they probably have not learned previously. De Souza [1] states that effective student teachers need certain qualities and these include enthusiasm, confidence, warmth and support. The current student teachers are in exciting times as well as daunting times. Teaching has become exciting in countries like South Africa where there are debates around decolonization, Africanization and constructivist models in classrooms. These are relevant issues and new teachers may be able to bring novel ways of teaching using Information and Communications Technologies (ICTs). Yet it can also be daunting because, for student teachers hoping to implement new ways of teaching, they may find that in their schools where they practise established teachers are still struggling to use the new ways. Tok [2] 
succinctly explains the role played by teaching practice:

Teaching practice plays an important role in teachers' acquisition of teaching skills. Student teaching experience serves as a culmination of the teacher education process. It is a time for individuals preparing for a career in education to apply the theories and methods that they have studied during their teacher preparation program (Norris, Larke, \& Briers, 1990). Practice teaching is the first opportunity for the student teacher to participate in activities involved in teaching in actual situations. It is also recognized as an experience of guided teaching in which the student teacher assumes increasing responsibility for directing the learning of a group of pupils over a specific period of time...

Teaching practice is critical for all teachers because this is the time when they get to look at teaching as teachers. De Souza's [1] qualities above may manifest themselves in conscientious student teachers. But student teachers need effective mentors and effective schools to support their passion for teaching; however, sometimes the conditions at schools where they practise are not conducive. Literature is fraught with studies that show that some schools are riddled with problems and a poor culture of learning and teaching [3], [4], [5]

Building resilient teachers who are likely to overcome the troubled and underperforming schools should start during practice teaching. Resilience in teaching is crucial because it enables teachers as well as learners to cope with day-to-day hardships. The paradox for many student teachers is that they find challenges in various schools including "good schools". Student teachers in schools may soon find out that not all schools follow effective discipline practices and teachers may need various strategies to sustain such schools. Linked to this resilience is building the idea of teachers as learners which needs to be engendered early on to facilitate continuous growth in teachers.

Yet, frequently, teachers in troubled schools fail to support each other for continuous professional growth [5]; [6]. This means that in schools that suffer underperformance, student teachers may experience huge challenges that will impact negatively on their growth. As a result, from the beginning of their careers teachers need engage in continuous professional growth programs. Ayaya et al. [6] argue that teachers in any school need to be reflective, critical and innovative about their teaching practices to be able to accommodate diverse classrooms. However, beginning teachers arrive at underperforming schools that have many challenges. Therefore, the questions posed in this study were:

- What pedagogical challenges do student-teachers encounter in poorly performing schools?

- How can student teachers prepare themselves for environments where adversities overwhelm learners and discourage teachers?

\section{Student Teachers, Learners and Resilience}

It is critical to coach teachers the art of planning and teaching because quality teachers are those who are organized and are able to do these well. Yet many mentors may miss preparing novice teachers one thing and that is resilience. Countless teachers who work in schools serving poor families in the townships (historically black areas) deal with situations of adversity that affect learners, their families, the school and the community [7], [8], [6] It will be a disservice to student teachers if they are not able to be resilient so as to meet the challenges in their future schools. Furthermore, not only is resilience critical among teachers but it also needs to be spread to the learners as well, especially learners exposed to negative influences in their environments. For teachers to be able to pass resilience to their learners they first need to be resilient themselves and this is a skill that needs to be instilled in student teachers very early. Teachers who model resilience would foster resilience upon their learners. Tocino-Smith [9] points out that teachers who teach resilience have a huge task of changing the misdirection of their learners' paths. Resilience ensures that learners understand their purpose in life and resilient teachers have a sense of vision.

TheHighlyEffectiveTeacher.com website [10] contends that teachers can do much to promote resilience among learners and this would enhance learner achievement whilst improving the learners' social and emotional aspects. TheHighlyEffectiveTeacher.com [10] also adds that teachers can promote resilience among learners in five ways:

i. Build positive relationships

ii. Teach social emotional skills

iii. Foster positive emotions

iv. Identify student strengths and

v. Build a sense of meaning and purpose.

All these five ways will strengthen the learner experience at any school. It would be difficult for many teachers to sustain the culture of learning and teaching in classrooms without engendering some or all of these ways. Resilient classrooms create invitational classrooms for healthy learning and nurturing in supportive environments [11], [12], [13], [9] The building of resilient classrooms should be based on a symbiotic relationship between teachers and their learners, hence it may be difficult to speak of resilient teachers when their learners are not prepared for resilience. Resilience is complex and some researchers have pointed out that we cannot be one hundred percent certain that it leads to learner achievement [14] However, some researchers have linked educational resilience to learners' achievement [14]; [15], [16], [17] Mwangi et al. [16] state that focusing on learners' strengths by engendering academic resilient teachers can reverse the high failure rates. These researchers also point out that resilience enables the learners to overcome setbacks, stress 
and other pressures and may lead to academic achievement. Cassidy [15] highlights the importance of both academic resilience and psychological resilience stating that these will lead to self-efficacy and learner achievement when well executed.

For teachers who may teach or do teach in poverty-ridden schools where families barely make ends meet, resilience for both teachers and learners is critical. The high risk children from struggling families may need the extra support to succeed in school. Instilling resilience may be the difference between successful learners and dropping out of school and the teachers' role must always be emphasized here. Teacher resilience in poverty contexts implies teachers adapt to and overcome a sequence of risks as they try to transform high-risk schools into "supportive spaces where they sometimes thrive, and sometimes feel distressed but mostly function effectively as teachers" [18] Teachers in many township schools join schools which are wrought with violence, managerial challenges and bullying of teachers by learners. In many classrooms learners suffer from apathetic teachers who do the minimum to support them, especially in learning areas where there are no specialist teachers. With all these challenges effective teachers would need to devise strategies for supporting the learners and hence resilience can form the basis of many such strategies. Ebersohn ([18] contends:

The daily lives of South African teachers are encumbered with many of the ailments of an emerging economy in transition. Foremost among these is poverty. The five yearly Income and Expenditure Survey (Statistics South Africa, 2013) revealed a South African poverty rate of $56.8 \%$ in 2009. In education, the prevalence of poverty can be seen in the fact that over $65 \%$ of South African students indicated that they received meals at school through the government-driven school nutrition program (Statistics South Africa, 2013). Also, in South Africa, 4.6 million people are currently unemployed, constituting an unemployment rate of 25.2\%. Discouraged work seekers number 2.3 million, and other people, not economically active, stands at 33,000 (Statistics South Africa, 2013). The implication is that most teachers can expect the students in their classrooms to come from households with income problems.

All these are contexts show the origins of many classroom problems in many public schools situated in historically black areas. In many of these schools learners highlight the forms of risks and dangers they encounter at their schools. Many such problems lead to teacher attrition because they may bring uncertainty among teachers. Adversity is a threat to effective education. There can hardly be any culture of learning and teaching in the face of adversity.

Effective teachers will cultivate conscious resilience in their learners who face adversity in life both at school and at home. Education and consciousness was perceived to be a critical combination in education by Paulo Freire [19]. Freire [19] saw education as a process that can change the learners' circumstances. Rochester [20] maintains that educators with a critical conscience will serve the learners well as they facilitate learner resilience. Teachers with increased critical conscience have more ability to reduce the impact of trauma and promote resilience development with the learners they teach. Efficacy is heightened when educators enhance their efficiency to comprehend and communicate within the world of their learners. Alicia [21] states that resilience is a skill of emotional intelligence and it helps people try again after faltering. Therefore, teachers and their learners who are resilient can have the equanimity to face life's tribulations. Resilience enables people to look at life anew as they tend to accept life's unexpected changes, and resilience allows people to move forward even in the face of hardships. Teacher resilience supports teacher quality, hence student teachers should learn this early on and, in fact, initial teacher education programs should include courses in resilience.

If teacher quality is a top priority, teachers should be prepared for school that are "outside the normal" and teaching strategies should be "contingent" as they address the specific quality of a given school. Jennings, Snowberg, Cocia and Greenberg [22] also state that the teaching and learning agenda should include not only enhancing academic achievement but also the learners' social-emotional competence as well as character. Conscientious school managers will help all staff to learn from one another through peer learning and teacher leadership. Caring teachers will work in a collective to overcome adversity in their schools. Collective commitment by teachers can help entrench long term school-wide initiatives to transform schools. Darling, Todd and Seok [23] describe the term "co-regulation" as a critical one when adults help children manage their thoughts, emotions and behavior to be able to adapt to adverse situations. Peers can learn much from the experiences of one another to strengthen their own resilience. When peers learn together they also sharpen one another's skills. Rochester [20] argues that teachers need experiential knowledge in order to support learners. Lack of experiential knowledge minimizes the ability to support learners in the face of chronic trauma [20].

Teacher education programs that ignore resilience fail to address education problems. Teaching graduates should never lose focus of their chosen profession because of the adversity they find in the field. Mansfield et al. [24] state that the first five years of a teacher's career are critical and that they are a time of vulnerability where teachers can leave teaching because of challenges. The role of peers, teacher mentors and teacher leaders is very important for beginning teachers in particular. To sustain resilience, peers can help in sustaining empowerment in this regard. This becomes part of teacher professional maturity that Msila [25] highlights in his study. Msila [25] points out that 
effective school managers will help their teachers to move from the stage of being novices to being accomplished teachers who are managers and agents of change in their schools. Mansfield et al. [24] claim:

Developing teacher education curriculum to build resilience in pre-service teachers is advantageous for teachers themselves, as well as future employers and school students. Resilience-focused curricular at university may also form the basis for ongoing personal development through existing professional development programs. As Gardner (2011) suggested, "universities could consider the potential of developing preventative self-help and well-being programs for future student-teachers' wellbeing (p. 24).

The current school managers encounter many challenges from outside that test their mettle as managers and all they need is to strengthen their resilience [26]. School leaders should consciously lead schools with a strategy to overcome adversity. This should also impact student teachers who visit their schools. Strong school managers will have values that support conscious discipline to embrace emotional resilience. Steward [26] states that "building and sustaining emotional resilience depends upon a complex web of inter-related experience, reflection and learning." These factors can easily be sustained if all teachers can learn in their teams what resilience means. In fact, initial teacher education programs should include programs that encompass Leading Schools for Resilience as a form of preparing all teachers to be able to lead schools for resilience. Organizational resilience will always be stronger when all members are conscious of it. Shared leadership approaches can be easier to implement when school managers work with teams that are aware of their role in resilience. Schools need to be cohesive when they approach resilience and hence teams are vital [27]. Conscientious school leaders will prepare an environment that will support teacher resilience. Wills and Hofmeyr [17] cite Masten who posits that resilience is not a trait but it results from interactions within a person and with the environment.

\section{Research Methodology}

Qualitative research has critical features that make it different from quantitative research methods. Qualitative research seeks to comprehend the phenomenon hence it is complex and broad [28], [29], [30] Procedures used are usually unstructured and supposes that subjectivity is necessary for the undertaking of human experience. Lopez and Whitehead [31] assert that the sample size in qualitative research should be able to achieve saturation hence meaningful analysis. Additionally, richness of data is more critical in qualitative research than the number of participants. A common number of participants in qualitative research ranges from 6 to 15 but may frequently vary within or outside this range [31]. Several qualitative methodologists argue that research designs determine the sample size; 3 to 5 participants for a case study, 15 to 20 for grounded theory, 6 for a phenomenological study and so on [31].

This case study was conducted at two high schools where student teachers from two South African universities in Gauteng Province were busy with their practice teaching. The sample of 10 participants was selected because they were doing practice teaching at two low performing schools. I used the previous three years' grade 12 results to gauge the performance of the schools. None of the schools had achieved the average of more than $40 \%$ pass rate in the previous three years. Both schools are situated in historically black areas and served black families under apartheid but, although apartheid is no longer in legislation, their learners, like those at other historically black schools in South Africa, still consist of $100 \%$ black learners. After getting permission from the two higher education institutions, I selected the participants using purposive sampling. School principals from both schools were approached to negotiate consent to conduct the study. The participants were aware of the ethical procedures in the study, their anonymity was confirmed and they were made aware that they could withdraw from the study any time if they felt under threat of any form.

Purposive sampling was used to select the participants using pre-selected criteria relevant to a particular research question [31]. Furthermore, these authors state that purposive sampling is intended to provide information-rich cases for in-depth study. The 10 student teachers were to be at the host schools for a period of four weeks. All of them were final year students registered in initial teacher programs. Their characteristics were as follows: 
Table 1. Characteristics of the participants

\begin{tabular}{|l|l|l|}
\hline Participant (P) & Area of specialization & Qualifications sought \\
\hline P1 & Maths \& Natural Science & Bachelor of Education (B.Ed.) \\
\hline P2 & Technology \& Natural Science & B.Ed. \\
\hline P3 & Social Science \& English & B.Ed. \\
\hline P4 & Social Science \& IsiZulu & Advanced Diploma in Education (ADE) \\
\hline P5 & Life Orientation \& Sesotho & ADE \\
\hline P6 & Life Sciences \& Social Science & ADE \\
\hline P7 & Business Studies \& Accounting & B.Ed. \\
\hline P8 & Information Technology \& Natural Science & B.Ed. \\
\hline P9 & Social Science & ADE \\
\hline P10 & Social Science \& IsiZulu & B.Ed. \\
\hline
\end{tabular}

I visited each of the participants in class at least three times, once during the first week and twice towards the last two weeks. I also observed at least two classes for each student teacher. Two in-depth (about 50 minutes) individual interviews were conducted with each participant. I also conducted two focus group interviews with five participants each. The interview instrument used consisted unstructured questions subdivided into five categories:

- Collaboration, teaching and effectiveness;

- Teachers, learners and resilience;

- Teachers as learners;

- Learners as teachers; and

- Consciousness and the art of learning and teaching

In addition to the interviews with the student teachers, I was able to have short 30 minute individual interviews with both principals mainly about the progress in the schools. Several learners in the two schools depend on a feeding scheme program and for many the meal they got at school was the last meal they had daily. In analyzing the data, I used a deductive approach where the research imposes its own theories on the data and then I used them to analyze the interview transcripts [32], [33] The process of data analysis meant moving backwards and forwards between the data collected, the coded extracts and the analysis of data being produced [34]. I analyzed the data manually by identifying the themes and categories that emerged from the data. After analyzing and categorizing the data I gave the results to the participants to verify. The results were recorded under specific themes. Wong [35] affirms that analyzing qualitative data encompasses the perusing of huge transcripts searching for themes and developing categories. When analyzing qualitative data researchers work with raw data as they identify meaningful patterns. What is of critical importance in qualitative content analysis is ensuring credibility hence the researcher must be conscious of his or her familiarity of the area studied to lessen own bias [36].

\section{Findings}

All the student teachers in the two schools pointed out that the host schools were fraught with under-performance and weak leadership. Only two participants stated that they benefited from their experience and incidentally both were mentored by the same teacher who frequently availed herself in guiding the teachers. They also pointed out that the teacher was able to "discuss a few lessons that he observed although even that was very informal". Generally, the student teachers in the two schools were always unaccompanied in their classrooms and in rowdy classrooms they struggled to control the learners in the first week. One student teacher, P7 in particular, says she found it intimidating at first to stand in front of a noisy classroom although by the end of the second week many learners were used to him and even went to the staffroom to fetch him when there was no teacher in their classrooms. The participants in School A were concerned that the grade 7 and grade 8 classes were far behind in syllabus. P1, the mathematics student teacher was requested by the school principal in School A to help with the grade 12s for he was worried about their examination readiness especially in mathematics, science and English literature. Common among the participants was the fact that in both schools there was lack of collegiality and there were no opportunities for student teachers to have mentors as was suggested by their university. The teachers whose classes they taught found that it was "a free time" to have them at the schools. The student teachers stated that what helped them was to rely on each other because there were no mentors as they were supposed to have in ideal situation. P1 pointed out:

I teach Mathematics and Science and I desperately needed to work with the learners' teachers for support. The learners' knowledge was very elementary and it was difficult to guide them. But I found how invaluable it 
was to discuss with fellow student teachers. We complemented each other were more creative where I wasn't. The discussions we had helped me see many blind spots in my teaching.

P4 and P10 concurred that the discussions with fellow student teachers improved pedagogy and helped them deal with adverse situations in their classrooms where learners had no social capital. P4 contended:

Peer learning was the crux of our experience and sharing our experiences ensured that our experiences would equip us for life especially for the kind of schools that we were in. We also highlighted this experience in our journals because it also showed how we can develop as teachers in future and that is learning from others.

Peer learning was a strong factor in student teachers who wanted to engender quality teaching and improve effectiveness in their classrooms. They also pointed out that teachers tended to be more fun when they were not isolated in their classrooms. The challenges at their schools also made them share strategies of what worked in their classrooms where learners were not always thoroughly prepared. The student teachers also learnt that teaching should be more about collaboration. P6 summarized this well when she averred, "Teaching is more about collaboration than competition. Teachers who collaborate enhance learner achievement and improve collegiality."

P2 stated that when he arrived at School A the teacher told him that he was free to do any part of the syllabus because the learners were advanced. However, he said when he got into class he discovered that the learners had not done much work in the Technology learning area. When he gave them a short test in the first week, many of them failed and frequently stated that their teacher usually taught in the medium of SeSotho and that they struggled to follow teaching in English. When confronted, the teacher said he tried to codeswitch although he was not efficient in SeSotho, being an isiZulu mother tongue speaker. As a result of the several challenges that the learners encountered, the teachers needed to devise ways of facilitating resilience. P6 who taught Life Sciences and Natural Science at School B pointed out:

As far as instilling resilience, all 10 of us from the two schools had to meet as we planned ways of building resilience. The learners are exposed to so many risks, so many traumas inside and outside school. There were hindrances though that thwarted our plans to bring resilience; teacher absenteeism, violence in the sports field, and even the outlawed corporal punishment by some teachers added to the misery of our learners. In our meetings as student-teachers we always felt bad because when we leave after the fourth week the worst practices may come back. That is why we were always trying to facilitate resilience as a life skill that learners would always need to fight the chronic traumas.
P8 taught Information Technology and echoed the same sentiments and added:

Our meeting two times each week made us aware of the ecology of the schools. The discussions enhanced our awareness about the challenges of the learners. Moreover, the meetings we had showed us two things. On the one hand is the theory we have from our programs whilst on the other we experience first-hand what is happening in the actual school. Just sharing the diverse challenges of our learners equip us so as to empower our learners. We just wish we were in normal schools. Nothing happens in our schools and when we leave no one will sustain what we were doing that is the saddest aspect.

The participants also complained that the schools lacked a culture and climate conducive to learning. In School A, P3 pointed out that throughout the day learners moved up and down wandering outside the classrooms and there were few attempts from school managers to restore order. Furthermore, there was a high rate of absenteeism among both teachers and learners. P1declared that this impacted negatively on the student teachers who frequently found no time to reflect after classes because they would be asked by heads of department to go and stand in for the absent teachers. The student teachers pointed out that they did not find adequate time to write their observations and compare their notes as required by their institution of higher learning. In School B, P9 and P10 highlighted that school management was not strong and the principal appeared to use a laissez faire approach to leadership. There seemed to be no consequences for wrong-doing such as absenteeism and deliberately staying away from class. Many learners gave accounts of how they were short-changed in the school and how many of them became despondent. There were other learners though, who enjoyed and were used to the slack approach to teaching and learning. This was common in the two schools where the weak culture of teaching and learning made many learners not to be focused in their learning program and these are some of the aspects that made the schools to be lackluster in performance. Furthermore, all the teachers highlighted how the learners struggled in school due to aspects such as poverty, teacher laxity, non-involvement of parents, violence and bullying as well as attending schools with no resources such as libraries and laboratories. Yet, no teachers seemed prepared to work closely with the student teachers as mentors hence the student teachers felt isolated.

Due to the isolation that the student teachers found themselves in, they depended upon one another for empowering themselves through open discussion and sharing of ideas. They mainly used Friday afternoons to share the week's experiences. In School A, P4 who teaches Social Science and isiZulu asserted:

We ended up depending upon one another for growth because none of the teachers were helping us as required 
by our university. I found it helpful to learn from the experiences of others when I observed them teaching. Even when the class was noisy and uncooperative, one learnt something about classroom control.

In the same school P5 averred:

I think working with colleagues should be excellent in building. Teachers need to observe, analyze and discuss their teaching as well as their colleagues' teaching so as to increase their teaching experience. I think this should be done by teachers throughout their careers. It is wonderful and enriching for any professional.

In both schools the participants introduced a concept of using diligent learners to help teach others or start discussions even when there were no teachers. They said this was a way of raising the learners' consciousness, making them believe that they could try and work among themselves when teachers were not coming to class. In fact, in School B the learners were even saying that even when some teachers come to class they hardly teach but rather sit and ramble. The student teachers claimed that they were also concerned with the challenges the pupils had with teacher absenteeism. P8 postulated:

Equipping a few learners helps because the learners needed people who would lead in the absence of teachers. Several had stated that some teachers would come to class but not teach. This meant that even those teachers who are present does not guarantee that when they attend class, they teach.

In School A the participants introduced the concept of empowering able learners to lead others in class especially when new topics were introduced. The participants frequently met who they referred to as Learning Leaders one hour after school for two days in a week. During these times they were able to discuss concepts and explain what they meant. In each class they were assigned to, the student teachers selected two or three learners. P2 in School A explained:

I suggested this kind of 'train-the-trainer' model where we selected the sharper students. I used my hunch to select these learners, I would look at the learners' participation and engagement in class. I only wish I could have started at the very first week. We did not know that the level of the learners was so low and this was not their own making. It all pointed towards the absence of teacher commitment. Numerous learners in my classrooms were able to change because when I started, many were disruptive and you could see that they were not used to what I call 'normal classes'. It is sad and I wished I could be in that school for the sake of the learners.

All the student teachers concurred that what they needed to work on was the consciousness of the learners because they maintained that these were also social justice issues. One of their modules at university had a portion that deals with social justice education and they pointed out that in the two schools there was no social justice. They declared that they needed to prepare their learners to understand why they were at school. The participants tried to instill confidence in the learners. P10 contended:

Indeed, learning has to do with the right mind and learners who are prepared well will learn well. The students in our schools 'knew that they knew nothing' at least that what their educators made them believe. A learner with no confidence will hardly be drawn to his school work and education in general. My colleagues and I tried to work on their mental attitude as well. Four weeks was a short time at the schools but I am proud of the few learners we changed. Only a pity that fellow teachers at the school did not observe our teaching for what we were doing could have in some way brought a few changes in the classrooms. The indifference among teachers was so unfortunate for many poor families.

The participants also talked about the management at their schools. Only one of the two principals acknowledged the problems in his school (School A) and he maintained that despite a few problems his school was running well. In interviews the principals maintained that their schools were changing for the better. The School A principal argued that his school was "moving towards the right direction" as teachers were beginning to understand their roles. He also added that his teachers were aware that they worked with learners coming from poor families and "frequently few people who perceive their efforts." Yet, School A was among the most under-performing schools in the district, when one focused on the year-end matric or grade 12 results. The principal in School B pointed out that there were many challenges at the school. She also said that ever since she took up the position she has tried "to change teacher performance but it had been tough because the teachers are used to a particular negative culture." She also warned the student teachers when they arrived that there were several petty conflicts in the staffroom among the teachers and the student teachers may find it hard sometimes to operate in the school. She also urged them "to do their best in the classrooms because their teaching might be the last that the learners get for the year." All the 10 participants concurred that their teaching practice was marred by weak leadership in the two schools. They did not see commitment in the school leaders with whom they worked. P4 affirmed:

The principal in our school is playing safe. How do you build an effective school if you seem afraid of your own teachers? The leader in our school appeared reticent to take real decisions. This is bad for the learners and their parents. Teachers do what they will and given any time during the day, you will find the staffroom full of teachers and you wonder who is in the classrooms. It's bad, so bad.

In their weekly meeting the student teachers decided to 
emphasize facilitating resilience among the learners because it appeared that the learners were not getting the necessary help from the teachers. Their concern was that the learners needed long term help otherwise education would not bring the necessary outcomes. It was also in the same vein that the student teachers maintained that all teachers from the first year should prepare themselves with skills for teaching high risk children in failing schools.

Using qualitative data analysis including searching for themes, coding and developing categories I identified certain patterns from the raw data. Below, the discussion focuses on three themes teased from the findings:

- Peer learning, student teachers and resilience

- Working with the learners' consciousness

- The learners as teachers

\subsection{Peer Learning, Student Teachers and Resilience}

The participants in the study highlighted the invaluable experience of learning from one another as teachers. In the short time they were in the schools, they were certain that sharing their practice experiences enhanced their effectiveness in the classrooms. They also stated that the peer learning experience is something that all practicing teachers should do. Jackson and Bruegmann [37] argue that a teacher's learners are likely to succeed in mathematics and reading when she has effective and supportive colleagues. Through their admission, the student teachers' quality grew because, among others, there were the peer discussions where they frequently discussed their experiences. The peers made the teachers enhance their effectiveness by discussing and observing others. Moreover, the teaching philosophy of peers makes others adjust their own philosophy as they motivate themselves as well as their learners. The student teachers in the study learnt to facilitate learner resilience whilst developing themselves during teaching practice. Rochester [20] states that exposure to lifestyles of poverty and acts of violence may thwart the process of learning in schools. Rochester also argues that pre-service teachers can increase advocacy of critical conscience as teachers engage in the lives of their students. Fortunately for the student teachers in the study, they were aware of the vital need to lessen the impacts of adversity among learners. Their hands-on approach in facilitating resilience was part of experiential learning and it increased their ability to embrace critical conscience as well as the ability to foster resilience among learners. The student teachers also spoke highly of the discussions that increased their experiential learning. The lack of experiential knowledge minimizes the capacity of teachers to support learners who face chronic trauma [20].

The student teachers talked at length about ways in which peer learning will be worthy in their future schools. They said whilst there was no help from the host schools from teachers their group discussions as student teachers built their confidence and their incipient professionalism.
They all maintained that what they were doing discussing the ways they were trying various strategies for the benefit of the learners. They pointed out in facilitating for resilience that they also needed to find ways of avoiding teacher isolation as they equipped themselves as resilient teachers. The student teachers maintained that working together and sharing classroom experiences is the best way to deal with situations of adversity and sustain their own resilience. They claimed that peer learning is among the best ways for teachers to support one another in schools where adversity reigns.

\subsection{Working with the Learners' Consciousness}

The student teachers spoke highly of the strategy of teachers working to change the learners' way of seeing the world in disadvantaged classrooms. They pointed out that it is not worth transforming teaching without changing the learners. They argued that learners whose consciousness is prepared for effective and resilient classrooms will enjoy engaging with supportive teachers. In the two schools the participants made the learners believe in themselves and this is the necessary Conscious Resilience that Alicia [21] highlights when she speaks about overcoming adversity and initiating change in classrooms. Alicia emphasizes the need for teachers to work with the inner resistance that learners may have. The student teachers realized in the first week that they were working with learners who had low self-esteem and were aware that the school would not better their chances in life. The participants maintained that as soon as they discussed among themselves to change this strategy and include instilling conscious resilience they noted slight changes in learner enthusiasm.

Whilst all the participants maintained that they could not do everything in four weeks of teaching practice, the opportunity demonstrated that when teachers have a strategy they will be able to overcome challenges they meet in their teaching career. Almost all stated that the future likelihood is that they would work in historically black schools with similar characteristics with the schools where they had their teaching practice. They found working with the learners' consciousness enabled them to start on a positive note when they engaged with them during lessons. In a world where learners are under pressure from inside and outside the school promoting resilience among learners ensures that their mental health is enhanced [10].

In line with the existing literature cited above, despite the hindrances that learners might encounter, these can be overcome by school-based resilience. Learners who have been taken through some facilitation on resilience are likely to succeed. Resilience is like a strong personality trait that is good to have and, as seen above, it is related to countless positive outcomes and can always be improved [38]. When the student teachers gave the learners class responsibilities, they found that this promoted positive well-being which led to resilience. The responsibility of 
leading group discussions enhanced the motivation of the learners as they could see their worth among others. The student teachers were also convinced that their teaching in future would never be successful without motivated, resilient learners, especially those coming from disadvantaged backgrounds with limited social capital. When learners are conscious they can even teach one another in case there are no teachers in their classrooms.

\subsection{The Learners as Teachers}

Instilling the learners' consciousness as discuss above leads to competence in classroom and when learners are competent they can empower one another. The student teachers realized that their time in the schools is for a short and hence teaching learners to teach others was a part of teaching perseverance and resilience. The participants spoke of a perpetual need to cultivate a culture of learners as teachers. In the two schools where the study took place this was critical in bringing back the worth of the learners who were seeing no meaning in school because they were lagging behind and appeared to know nothing from their learning areas. The student teachers made them believe that they could address their challenges of not having teachers in classrooms by being teachers themselves. The participants were amazed by the way in which the role change equipped the learners to learn from the challenges in their classrooms as they adapted to transforming the culture of learning and teaching in their schools. The role of being teachers brought strength to the learners because they could see that they could change their circumstances. Therefore, instead of waiting for teachers who would never come or if they did come arrived in the classroom under prepared, the learners learnt that they could teach one another.

The student teachers used some of the aspects highlighted by HighlyEffectiveTeachers.com [10] and these are identifying learners' strength and teaching social/emotional skills. The student teachers were trying to instill a sense of responsibility among the learners so that when they left after the four weeks they would leave the learners with skills that they would use in their school as well as beyond school. The idea of learners as teachers made the learners embrace a sense of purpose and many showed that they had a reason to go to school. Again the student teachers stated that this was critical in ensuring that the learners were self-reliant in times of challenges where the teachers for some reasons cannot come to the classrooms. They also claimed that this worked on the learners' competence and skills. The student teachers also believed that some of the strategies of engendering resilience improved learner performance and improved the learners' emotional well-being. The student teachers maintained that these strategies would lessen their challenges in future when they come back and assume positions in historically black schools in particular where there were always challenges when it comes to the culture of learning and teaching.

\section{Conclusions}

This study shows how student-teachers encounter challenges in poor underperforming schools serving poor families in historically black areas. In these schools pedagogical challenges persist as adversity faces learners at all times from poverty-stricken families, low morale and inadequate learning materials. It is only teachers who prepare themselves well to overcome these barriers who will thrive. The student teachers realized that facilitating resilience as well as fortitude among teachers and learners can minimize ineffectiveness. The study proved that teachers who would be ready for diverse school conditions are those who are empowered and would also be able to inspire their learners in turn. The research also demonstrates that student teachers need to prepare themselves for the challenging environments in poor schools otherwise their practice teaching would not have been worthwhile. The students were also able to use the theory they learnt from university on student and teacher resilience. Among the major conclusions from the study are that some strategies are critical for supporting teachers for professional development in their entire life. Furthermore, engendering resilience can be the most useful tool in averting attrition and teacher despondency. Furthermore, the study also shows that the life of a teacher and professional development should start from the years of practice teaching. Initial teacher programs should instill the passion as they offer ways to overcome barriers that teachers may encounter in their various future schools. Resilience is one of the most important factors in poor schools where learners may have lost their sense of self-worth. Teaching has become challenging today hence endurance is needed by teachers and their learners.

Finally, as is the nature of case studies, this study has limitations in that the sample was small and was drawn from only two universities, hence the findings cannot be generalized. The findings are useful, though, in understanding the contexts of the participants under study. Large investigations where learners and more student teachers can be participants are needed to understand both teacher's and learner's resilience as well as their influence on school achievement.

\section{REFERENCES}

[1] De Souza, B. "Teaching Practice: A Handbook for Student Teachers.” Zomba, Malawi: The Author.2021.

[2] Tok, S. "The problems of teacher candidates about teaching skills during teaching practice." Procedia Social and 
Behavioural Sciences, vol. 2 no. 2, pp. 4142-4146. 2021. https://doi.org/10.1016/j.sbspro.2010.03.654

[3] Heystek, J. \& Lethoko, M. "The contribution of teacher unions in the restoration of teacher professionalism and the culture of learning and teaching." South African Journal of Education, vol. 21, no. 4, pp. 222-227. 2001. https://www.ajol.info/index.php/saje/article/view/24907

[4] Msila, V. "School choice and intra-township migration: Black parents scrambling for quality education in South Africa." Journal of Education, vol. 4, pp. 81-98, 2009.

[5] Msila, V. "The struggle to improve schools: Voices of South African teacher mentors." EMAL, vol.44, no. 6, pp. 936-950, 2016. 10.1177/1741143215595416.

[6] Ayaya, G., Makoelle, T.M. \& Van der Merwe, M. "Participatory action research: A tool for enhancing inclusive teaching practices among teachers in South African full-service schools." Sage Open, October-December, pp.1-13, 2020. http://10.1177/2158244 020963576.

[7] Msila, V. "School management and the struggle for effective schools". Africa Education Review, vol. 8, no. 3, pp. 434-449., 2015.

[8] Msila, V. "Leaving a sinking ship: School principals in flight." Africa Education Review. 2017. Online from http://dx.doi.org/10.1080/18146627.2016.1224575

[9] Tocino-Smith, J. "Teaching resilience in schools and fostering resilient learners.” PositivePsychology.com. 2021. [Online] Available https://positivepsychology.com/teachin g-resilience/

[10] TheHighlyEffectiveTeacher.com. How to promote resilience in your students. 2021. [Online] Available https://thehighlyeffectiveteacher.com/how-to-promote-resil ience-in-your-students/

[11] Doll, B., Zucker, S. \& Brehm, K. "Resilient classrooms: Creating healthy environments for learning. Practical Intervention in the Schools Series." New York: Guilford Press, 2004

[12] Ruschton, J. "Building resilience in the classroom." CPD Online College. 2020. [Online] Available https://cpdonline .co.uk/knowledge-base/safeguarding/building-resilience-in -the-classroom/

[13] Daniilidou, A., Platsidou, M. \& Gonida, E. "Primary school teachers' resilience: Association with teacher self-efficacy, burn-out and stress." Electronic Journal of Research in Educational Psychology, vol. 18 no. 3, pp. 54-52. 2020. http:// 10.25115/ejrep.v18i52.3487

[14] Britton, J.A. "Resilience and academic achievement in minority students." Theses and Dissertations.1009. 2021.https://ir.library.illinoisstate.edu/etd/1009

[15] Cassidy, S. "Resilience building in students: The role of academic self-efficacy." Frontiers in Psychology, November 27, 2015. https://doi.org/10.3389/fpsyg.2015.01 781

[16] Mwangi, C.N., Okatcha, F.M., Kinai, T.K. \& Ireri, A.M. "Relationship between academic resilience and academic achievement among secondary school students in Kiambu County, Kenya." International Journal of School and
Cognitive Psychology, S2:3. 2015. http://10.4172/2469-98 37.S2

[17] Wills, G., Hofmeyr, H. Academic resilience in challenging contexts: Evidence from township and rural primary schools in South Africa. Stellenbosch Economic Working Papers. Stellenbosch: Stellenbosch University/BER, 2018.

[18] Ebersohn, L. "Teacher resilience: Theorizing resilience and poverty." Teachers and Teaching: Theory and Practice, vol. 2, no. 5, pp. 56-54. 2014. http://dx.doi.org/10.1080/135406 02.2014 .937960

[19] Freire, P. "Pedagogy of the oppressed." New York: Continuum, 1970.

[20] Rochester, P.R. "Facilitation of student resilience through educator development of critical conscience." European Journal of Educational Sciences, October. 2019. http://dx.doi.org/1.144/ejes.s.v6a

[21] Alicia, C.R. Conscious resilience. Spiritual Tree. [Online] 2020. Available https://medium.com/spiritual-tree/conscio us-resilience-fa7010cab986

[22] Jennings, P.A., Snowberg, K.E., Coccia, M.A. \& Greenberg, M. T. "Improving classroom learning environments by cultivating awareness and resilience in education (CARE): Results of two pilot studies." Journal of Classroom Interaction, vol. 46, no. 1, pp. 37-48. 2011.

[23] Darling, K., Todd, M. \& Seok, D. "Resilience and conscious discipline." Conscious Discipline (Child Trends), July 18, 2019.

[24] Mansfield, C., Beltman, S., Broadley, T. \& Westherby-Fell, $\mathrm{N}$. "Building resilience in teacher education: An evidenced informed framework." Teaching and Teacher Education, vol. 54, p.77. 2016.

[25] Msila, V.T. "Teachers as managers of change." Doctoral dissertation. Port Elizabeth: Vista University. 2002.

[26] Steward, J. Sustaining emotional resilience for school leadership. School leadership management, vol. 34, no 1, pp. 52-68. 2014. https://doi.org/10.1080/13632434.2013.8496 86

[27] Beauchamp, G., Hulme, M., Clarke, L., Hamilton, L. \& Harvey, J.A." 'People miss people': A study of school leadership and management in the four nations of the United Kingdom in the early stage of the COVID-19 pandemic." Educational Management Administration \& Leadership, vol. 43, pp. 35-32. 2021.doi/pdf/10.1177/1741 143220987841

[28] Denzin, N. \& Lincoln, Y. (Eds). "Handbook of qualitative research." Thousand Oaks, Sage, 2011.

[29] Corbin, J. \& Strauss, A. "Basics of qualitative research: techniques and procedures for developing grounded theory." Thousand Oaks, Sage, 2008.

[30] Brink, H.I. "Research methodology for health professionals." Cape Town, Juta, 2000.

[31] Lopez, V. \& Whitehead, D. Sampling data and data collection in qualitative research. In Nursing \& Midwifery Research: Methods and appraisal for evidence-based practice. Elsevier Mosby, pp123-140. 2013. 
[32] Struwig, F.W. \& Stead, G.B. "Planning, designing and reporting research." Cape Town: Pearson, 2004.

[33] Burnard, P., Gill, P., Stewart, K., Treasure, E. Chadwick, B. Analyzing and presenting qualitative data. British Dental Journal, vol. 204, no. 8, pp. 429-432. 2008. https:// 10.1038/sj.bdj.2008.292

[34] Mortensen, D.H. "How to do a thematic analysis of user interviews." nd. [Online] Available https://www.interactio n-design.org/literature/article/how-to-do-a-thematic-analys is-of-user-interviews

[35] Wong, L.P. "Data analysis in qualitative research: A brief guide to using NVIVO." Malaysian family Physician: The official journal of the Academy of Family Physicians of
Malaysia, vol. 3, no. 1, pp. 14-20. 2008.

[36] Bengtsson, M. "How to plan and perform a qualitative study using content analysis." Nursing Plus Open, vol. 2, pp. 8-14. 2016

[37] Jackson, C.K., \& Bruegmann, E. "Teaching students and teaching each other: The importance of peer learning for teachers." American Economic Journal: Applied Economics, vol.1, no. 4, pp. 85-108. 2009.

[38] Ackerman, C.E. "What is resilience and why it is important to bounce back?" PositivePsychology.com. May 22, 2021. [Online] Available https://positivepsychology.com/what-is -resilience/ 